J. Dairy Sci. 95:6523-6528

http://dx.doi.org/10.3168/jds.2012-5742

(C) American Dairy Science Association ${ }^{\circledR}, 2012$.

\title{
Validation of an automated method to count steps while cows stand on a weighing platform and its application as a measure to detect lameness
}

\author{
N. Chapinal ${ }^{\star 1}$ and C. B. Tuckert \\ *Animal Welfare Program, University of British Columbia, Vancouver, Canada, V6T 1 Z4 \\ †Department of Animal Science, University of California, Davis 95616
}

\begin{abstract}
Weight shifting between legs and steps taken when cows stand may be a useful tool to assess cow comfort and lameness. Weight shifting is assessed by measuring the distribution of weight applied to each leg when standing on a weighing platform, whereas frequency of steps is traditionally measured with live observation or video recording. The objectives of this study were to validate an automated method to count steps from weight distribution measurements (experiment 1) and to assess the accuracy of the frequency of steps in detecting lameness (experiment 2). In experiment 1, 6 nonlame multiparous cows stood on a weighing platform covered with either concrete or rubber ( $1 \mathrm{~h} /$ cow per surface) while stepping behavior was video recorded. Receiver operating characteristic curves were constructed, using the steps observed in the video recordings as the gold standard, to calculate the optimal threshold (based on the sum of sensitivity and specificity) of the weight applied to a leg to define a step. Optimal thresholds were similar between surfaces. The optimal thresholds, when pooling the 2 surfaces, were 127 and $98 \mathrm{~kg}$ for the front and rear pair for legs, respectively, with a specificity and sensitivity $\geq 0.96$. Thresholds were used to construct an algorithm to count steps. In experiment 2 , 57 cows (26 of them considered lame according to their gait score) stood for $15 \mathrm{~min}$ on the weighing platform. Frequency of steps taken with the front and rear pair of legs was calculated from the weight distribution measurements using the algorithm calculated in experiment 1. Lame cows took more steps per minute with the rear legs than did nonlame cows (1.6 vs. 1.0 steps $/ \mathrm{min}$; SE of the difference $=0.2$ ). As previously shown for weight shifting, the frequency of steps taken with the rear legs was a good predictor of lameness (area under the curve of the receiver operating characteristic curve $=0.67$; $95 \%$ confidence interval $=0.52,0.81$ ). A positive relationship was observed between the frequency of steps
\end{abstract}

Received May 16, 2012.

Accepted July 26, 2012.

${ }^{1}$ Corresponding author: nchapinal@yahoo.com and weight shifting (measured as SD of the weight applied over time to the legs) in both the front $\left(\mathrm{R}^{2}=\right.$ $0.35)$ and rear $\left(R^{2}=0.49\right)$ legs, yet the slopes differed from 1 and the intercepts differed from 0 , indicating that the 2 measures were related but not the same. In conclusion, weighing platforms can accurately calculate the frequency of steps automatically, and this measure shows promise as a tool to assess lameness.

Key words: comfort, gait, restlessness, weight shifting

\section{INTRODUCTION}

Weight shifting between legs when cows stand without walking has been described as a measure of restlessness and pain. For example, weight shifting (measured as the SD of the weight applied over time to a pair of legs) increases when cows stand for $1 \mathrm{~h}$ on concrete or rubber, indicating restlessness (Chapinal et al., 2011). Weight shifting is also a predictor of lameness (Pastell and Kujala, 2007; Chapinal et al., 2010), and this behavior decreases when lame cows are given pain relief (Rushen et al., 2007; Chapinal et al., 2010). Steps are the clearest form of weight shifting between legs, and cows step more frequently (without walking) the longer they stand on concrete or rubber (Cooper et al., 2007; Chapinal et al., 2011; Krebs et al., 2011). Although the frequency of steps and weight shifting when cows stand without walking are positively correlated (Chapinal et al., 2011) and seem to increase in the same situations, some cases exist when measuring both rather than just one provides additional information. For instance, Chapinal et al. (2011) suggested, based on 1 anecdotal incident, that cows with mastitis might choose to shift weight without actually lifting their hooves because of pain in the udder; that is, the ratio between weight shifted and number of steps was lower than expected.

Two approaches have previously been used to measure the frequency of steps while cows stand: (1) observing the animals live or by video recording (Cooper et al., 2007; Krebs et al., 2011) and counting every time the hoof is lifted, or (2) using measurements of the weight distribution among legs automatically collected by load cells installed in an automatic milker (Pastell 
and Kujala, 2007). The first method is very timeconsuming; thus, the practical application is limited. In the second approach, Pastell and Kujala (2007) defined a step as every time the weight applied to a given leg declined below $20 \mathrm{~kg}$. However, they did not report sensitivity and specificity for this threshold; thus, it is unclear whether this truly measured stepping behavior. Thus, further research is needed to validate a threshold to measure the frequency of steps automatically. The development of an automated method to measure the frequency of steps could be useful for on-farm lameness detection. Individual cows differ in weight-shifting patterns, with lame cows shifting weight more often than nonlame cows (Chapinal et al., 2010). Stepping behavior while standing could also differ with lameness status (Pastell and Kujala, 2007), but to date, this has not been tested with a validated automated method of counting steps. The objectives of this study were (1) to validate an automated method to count steps from weight distribution measurements (experiment 1), and (2) to assess the accuracy of frequency of steps in detecting lameness (experiment 2).

\section{MATERIALS AND METHODS}

\section{Animals and Housing}

Lactating Holstein cows were housed in sand-bedded freestalls $(2.4 \mathrm{~m}$ long $\times 1.18 \mathrm{~m}$ wide $\times 0.40 \mathrm{~m}$ deep, at least 1 per cow) in groups of 12 to 48 cows at the Dairy Education and Research Centre of the University of British Columbia (Agassiz, Canada). Cows were fed a TMR diet twice daily at 0700 and $1600 \mathrm{~h}$ that was formulated to meet the requirements for lactating dairy cows (NRC, 2001). Water was freely available from selffilling troughs. Cows were milked twice daily in the parlor at approximately 0800 and $1700 \mathrm{~h}$. All animals were cared for according to the guidelines of the Canadian Council on Animal Care.

\section{Data Collection}

Weight Distribution. The distribution of weight among the legs was measured while cows were standing on a weighing platform (Pacific Industrial Scale Co Ltd., Richmond, BC, Canada) situated at the end of the passageway used for gait scoring (Chapinal et al., 2010). The platform contained 4 stainless steel independent recording units $(12 \mathrm{~cm}$ high $\times 59 \mathrm{~cm}$ wide $\times$ $99 \mathrm{~cm}$ long), each containing 4 stainless steel load cells (3-mV Shear Beam Load Cells, maximum capacity = $454 \mathrm{~kg}$ /load cell; Anyload LLC, Santa Rosa, CA). The weight recorded was not affected by the position of the hooves in the unit. Data were transmitted to a com- puter at a rate of approximately 13 reading/s. Specific software (CowWeigh.exe version 2.2; Pacific Industrial Scale Co Ltd., Richmond, BC, Canada) was used to provide a real-time display of the weight applied to each of the 4 units. The platform was lifted $4.5 \mathrm{~cm}$ from the floor with concrete blocks to avoid load cell corrosion. A manual steel squeeze $(2.1 \mathrm{~m}$ high, $2.0 \mathrm{~m}$ long, 1.3 wide) was mounted on the platform to restrain the cows.

Gait Score. The cows had their gait scored while walking down a $13 \mathrm{~m}$ long $\times 1.3 \mathrm{~m}$ wide nongrooved concrete passageway after the morning milking. To encourage cows to walk in a consistent manner, a handler walked immediately behind the cows, encouraging them down the passageway when necessary. Cows were videotaped from the left side with a color digital camera (Sony DCRSR100 HDD Handycam Camcorder, 30 frames/s; Sony Corporation, Park Ridge, NJ) connected to a digital recording system (Genetec Inc., Saint-Laurent, Quebec, Canada) placed $8 \mathrm{~m}$ from the cow to allow recording of at least 4 complete strides during each passage. Specialized software was used to review video data (Omnicast; Genetec Inc.). One experienced observer watched the videos and assigned a gait score to each cow for each day, using a 1 to 5 numerical rating system (NRS; where $1=$ perfect gait and $5=$ severely lame) with half-integer scores (Flower and Weary, 2006; Chapinal et al., 2009).

\section{Experimental Procedures}

Experiment 1. For this study, we used data from 6 multiparous Holstein dairy cows of the 12 cows used in the study by Chapinal et al. (2011), which compared weight shifting on concrete and rubber surfaces. Cows were selected according to quality of the data: (1) complete data sets for both of the surfaces that were tested, and (2) asynchrony between video recording and data collected from the weighing platform not greater than $3 \mathrm{~s}$ (see below). Details of the experimental procedure and the standing surfaces are described in Chapinal et al. (2011). Briefly, we measured how weight distribution and frequency of steps changed when cows were standing on a weighing platform for $1 \mathrm{~h}$, with the 4 hooves on either rubber or concrete. Cows were tested on each surface on different days, with at least $2 \mathrm{~d}$ between surfaces. A concrete block (3.7 cm high) or 2 rubber revulcanized rubber mats $(1.9 \mathrm{~cm}$ thick each; Animat, Saint-Élie d'Orford, QC, Canada) were placed on the top of each recording unit. The position of the hooves was recorded by 4 black-and-white video cameras (CCTV WV-BP310; Panasonic, Secaucus, NJ) connected to a digital recording system (Genetec Inc.). Two cameras were set up to record a lateral view of the 
hooves, 1 from each side, whereas the other 2 cameras recorded a front and back view of the hooves. Specialized software was used to record and subsequently watch the videos (Omnicast; Genetec Inc.). An experienced observer watched the videos continuously and counted the number of steps for each hoof (defined as the number of times the heel was visibly lifted off the standing surface). Intraobserver reliability, as measured by percentage agreement, was $91 \%$ for detecting steps in a given second. Cows were gait scored at enrollment to exclude severely lame cows.

Experiment 2. For this study, we used data from the 57 multiparous Holstein dairy cows used in the study by Chapinal et al. (2010), which assessed automated measures of weight shifting among legs for detecting lameness in dairy cows. Only data taken on the day of enrollment were used. Cows were gait scored and measures of weight distribution were taken while the cows stood on the weighting platform on a rubber surface (the same as described for experiment 1) for a total of three 5-min passages. All measures were taken after the morning milking. Measures of the frequency of the steps were not available at the time of the previous report.

\section{Data and Statistical Analysis}

All statistical analyses were performed with SAS version 9.2 (SAS Institute Inc., Cary, NC) using the cow as the experimental unit.

Experiment 1. When cows take a step, the hoof is usually off the ground for less than $1 \mathrm{~s}$. When a cow steps, the weight recorded by the load cells does not drop to $0 \mathrm{~kg}$ in most of the cases (Figure 1). Thus, a threshold has to be determined to define a step. The occurrence or absence of a step in each second observed in the video recordings was considered the gold standard used to determine the threshold. The platform measures weight multiple times per second, but only the minimum weight recorded within each second for each leg was considered. We detected some asynchrony between the video recordings and the weight distribution data, namely, the time stamp in the weight distribution data was 0 to $3 \mathrm{~s}$ ahead. To reduce the effect of any asynchrony, the occurrence of a step in a particular second in the video recording was matched to the minimum weight recorded for that particular leg on that particular second and the 3 previous seconds. This information was used to construct receiver operating characteristic (ROC) curves [sensitivity vs. (1 - specificity)] to identify the optimal weight threshold to define a step. The point on an ROC curve that is closest to the upper left corner has the highest combined sensitivity and specificity, and was considered the optimal threshold (Dohoo et al., 2009). For each pair of legs (front or rear), thresholds were determined for each surface separately and together, for each cow individually $(\mathrm{n}=6)$, and for all cows together. Differences between the individual thresholds determined for each surface were tested with a paired $t$-test. Pairs of legs were considered separately. The thresholds were used to determine the number of steps counted from the weight distribution data by using an algorithm. This algorithm considered a step when the minimum weight applied to 1 leg in a particular second was equal to or lower than the threshold as long as the weight applied to that leg in the previous second was above the threshold. Thus, in a case in which 2 steps were taken with the same leg in 2 consecutive seconds, the algorithm would count only 1 step. However, this only occurred 22 times out of 2,135 total steps observed in the video recordings. When steps were very close in time (e.g., separated by $1 \mathrm{~s}$ ), weight may not recover over the threshold between the 2 steps, in which case only 1 step would be counted. However, underestimation from steps separated by $1 \mathrm{~s}$ only occurred 66 times out of the 2,135 total steps.

Experiment 2. Cows were classified as lame if NRS $>3$ (Flower and Weary, 2006; Chapinal et al., 2009; n $=26$ ). The algorithm described in experiment 1 , using the pooled weight threshold for each pair of legs calculated when cows were standing on rubber, was used to count steps from the weight distribution data. The frequency of steps was summarized as the average number of steps per minute taken with each pair of legs (sum of 2 front or rear legs). Differences in the frequency of steps between lame and nonlame cows were assessed with a 2-sample $t$-test. Logistic regression was used to determine the predictive value of the frequency of steps taken with each pair of legs on whether the cow was classified as lame or nonlame. Receiver operating characteristic curves were constructed and the area under the curve (AUC) was determined as a measure of accuracy in predicting lameness (if AUC $=0.50$, the predictive value is no better than flipping a coin). The AUC was used to compare the accuracy of the frequency of steps in discriminating lame cows with the accuracy of other weight distribution measures assessed in Chapinal et al. (2010), namely, the standard deviation of the weight applied over time to each pair of legs (a measure of weight shifting), and the leg weight ratio between the lighter leg and the heavier leg within each pair of legs (a measure of asymmetry within each pair of legs). The standard deviation of the weight applied over time to each pair of legs was regressed on the frequency of steps, and the slope was tested against 1 and the intercept against 0 , to assess how closely these 2 variables were related (i.e., whether they were measuring the same phenomena). The Pearson correlation 


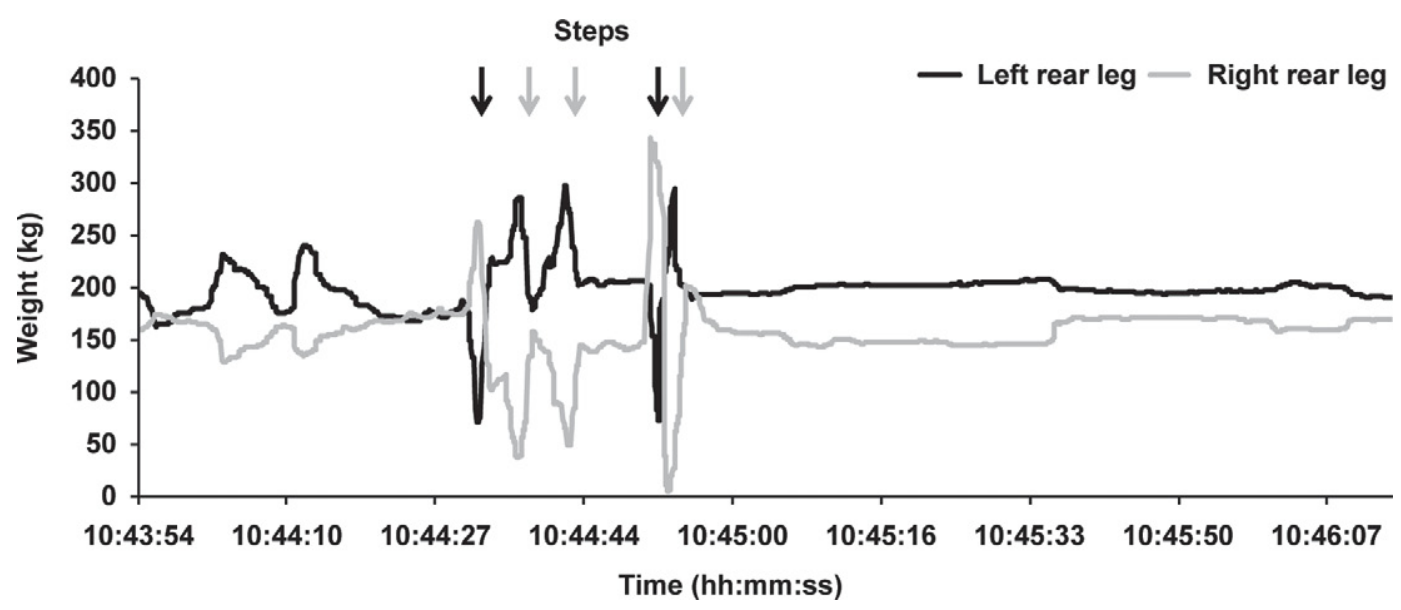

Figure 1. Example of weight distribution between the rear pair of legs of a cow standing on the weighing platform. Arrows indicate steps observed by video recordings for the left rear (black) and right rear (gray) leg.

was used to correlate the frequency of steps with the leg weight ratio within each pair of legs, and the frequency of steps of each pair of legs with the gait score.

\section{RESULTS}

\section{Experiment 1}

The optimal weight thresholds to discriminate steps by using weight measurements for each pair of legs are shown in Table 1 . The values of sensitivity and specificity were very similar across the thresholds calculated for each pair of legs and each surface when using all the cows or individual cow data. For the pooled thresholds (all cows considered), sensitivity and specificity were $\geq 0.96$ in all cases, whereas in the case of individual thresholds, sensitivity was $\geq 0.90$ and specificity was $\geq 0.95$ in all cases. No differences were observed between the thresholds calculated for concrete and rubber for the front $(P=0.30)$ or rear legs $(P=0.89)$. The differences between frequency of steps calculated by using video recordings and weight distribution measures for each cow, pair of legs, and surface are shown in Table 2.

\section{Experiment 2}

Lame cows took more steps per minute with the rear legs than did cows that were not lame (1.6 vs. 1.0 steps $/ \mathrm{min} ; \mathrm{SED}=0.2 ; P=0.02$ ), whereas no differences were observed in the stepping behavior of the front legs (0.7 vs. 0.6 steps/min for lame and nonlame cows, respectively; SED $=0.2 ; P=0.67)$. The logistic regression models revealed an association between the occurrence of lameness and the frequency of steps taken with the rear legs (odds ratio $=2.0 ; 95 \% \mathrm{CI}=1.1,3.6$; $P=0.03)$, but not with the front legs $(P=0.65)$. The AUC of the ROC curve for frequency of steps taken with the rear legs was $0.67(95 \% \mathrm{CI}=0.52,0.81 ; P=$ 0.02 when tested against $\mathrm{AUC}=0.50)$.

A positive relationship was observed between the standard deviation of the weight applied over time and the legs and frequency of steps in both the front $(\mathrm{y}=$

Table 1. Optimal weight thresholds (kg; defined as the threshold with the highest combined sensitivity and specificity in the receiver operating characteristic curve] to discriminate steps from the weights recorded on each leg $^{1}$

\begin{tabular}{|c|c|c|c|c|c|c|}
\hline Threshold (kg) & \multicolumn{3}{|c|}{ Front legs } & \multicolumn{3}{|c|}{ Rear legs } \\
\hline Pooled & 127 & 128 & 123 & 98 & 86 & 99 \\
\hline $\begin{array}{l}\text { Cow } 1 \\
\text { Cow } 2\end{array}$ & 127 & 124 & 146 & 129 & 128 & 126 \\
\hline Cow 2 & 143 & 143 & 121 & 83 & 83 & 105 \\
\hline Cow 3 & 136 & 149 & 122 & 69 & 64 & 64 \\
\hline Cow 6 & 103 & 102 & 103 & 91 & 90 & 96 \\
\hline
\end{tabular}

\footnotetext{
${ }^{1}$ Analyses were performed separately for each pair of legs (front and rear) using either pooled data from 6 Holstein cows or individual cow data,
} separately for each surface (concrete and rubber) and with both surfaces pooled together. 
Table 2. Number of steps per minute identified in the video recordings and by applying the algorithm ${ }^{1}$ to the weights recorded by the weighing platform, and difference between the 2 measures for each standing surface (concrete and rubber) and leg of 6 Holstein cows

\begin{tabular}{|c|c|c|c|c|c|c|c|c|c|c|c|c|}
\hline \multirow[b]{2}{*}{ Surface } & \multicolumn{4}{|c|}{ Video recording } & \multicolumn{4}{|c|}{ Algorithm ${ }^{1}$} & \multicolumn{4}{|c|}{ Difference } \\
\hline & $\begin{array}{l}\text { Left } \\
\text { front }\end{array}$ & $\begin{array}{l}\text { Right } \\
\text { front }\end{array}$ & $\begin{array}{l}\text { Left } \\
\text { rear }\end{array}$ & $\begin{array}{l}\text { Right } \\
\text { rear }\end{array}$ & $\begin{array}{l}\text { Left } \\
\text { front }\end{array}$ & $\begin{array}{l}\text { Right } \\
\text { front }\end{array}$ & $\begin{array}{l}\text { Left } \\
\text { rear }\end{array}$ & $\begin{array}{c}\text { Right } \\
\text { rear }\end{array}$ & $\begin{array}{l}\text { Left } \\
\text { front }\end{array}$ & $\begin{array}{l}\text { Right } \\
\text { front }\end{array}$ & $\begin{array}{l}\text { Left } \\
\text { rear }\end{array}$ & $\begin{array}{l}\text { Right } \\
\text { rear }\end{array}$ \\
\hline \multicolumn{13}{|l|}{ Concrete } \\
\hline Cow 1 & 0.8 & 0.9 & 0.8 & 0.6 & 0.9 & 0.8 & 0.7 & 0.5 & 0.0 & 0.2 & 0.0 & 0.1 \\
\hline Cow 2 & 0.2 & 0.5 & 0.7 & 0.6 & 0.2 & 0.5 & 0.6 & 0.6 & 0.0 & 0.0 & 0.1 & 0.1 \\
\hline Cow 3 & 0.5 & 1.2 & 1.1 & 2.0 & 0.5 & 1.2 & 1.1 & 1.8 & 0.0 & 0.0 & 0.0 & 0.3 \\
\hline Cow 6 & 0.7 & 0.5 & 1.4 & 0.8 & 0.8 & 0.9 & 1.4 & 0.8 & -0.1 & -0.4 & -0.1 & 0.0 \\
\hline \multicolumn{13}{|l|}{ Rubber } \\
\hline Cow 1 & 0.8 & 0.7 & 1.2 & 1.2 & 0.8 & 0.6 & 1.0 & 1.1 & 0.1 & 0.1 & 0.2 & 0.1 \\
\hline Cow 2 & 0.5 & 0.5 & 0.4 & 1.0 & 0.5 & 0.5 & 0.4 & 1.1 & 0.0 & 0.0 & 0.0 & -0.1 \\
\hline Cow 3 & 0.9 & 0.7 & 0.9 & 1.1 & 0.9 & 0.9 & 0.9 & 1.5 & -0.1 & -0.2 & 0.0 & -0.4 \\
\hline Cow 4 & 0.4 & 0.4 & 1.0 & 1.3 & 0.8 & 0.5 & 0.9 & 1.4 & -0.4 & -0.1 & 0.0 & -0.1 \\
\hline Cow 5 & 0.4 & 0.3 & 0.3 & 0.3 & 0.4 & 0.3 & 0.4 & 1.2 & 0.0 & 0.0 & -0.1 & -0.8 \\
\hline
\end{tabular}

${ }^{1}$ The pooled threshold calculated for each surface using data from all 6 cows was used in the algorithm.

$14.2+8.1 \mathrm{x} ; \mathrm{R}^{2}=0.35 ; P<0.001 ;$ Figure $\left.2 \mathrm{~A}\right)$ and rear $\left(\mathrm{y}=16.8+8 \mathrm{x} ; \mathrm{R}^{2}=0.49 ; P<0.001 ;\right.$ Figure $\left.2 \mathrm{~B}\right)$ pair of legs, yet the slope differed from 1 and the intercept differed from 0 in both cases $(P<0.001)$. The frequency of steps taken with the rear legs was correlated with the rear leg weight ratio $(\mathrm{r}=-0.40 ; P=0.002)$ and with gait score $(\mathrm{r}=0.42 ; P=0.001)$, whereas no correlation was found in the case of the front legs $(P>$ 0.30 in both cases).

\section{DISCUSSION}

Both the individual and pooled optimal thresholds determined in this study had high sensitivity and specificity. Furthermore, the thresholds calculated for concrete and rubber standing surfaces were similar. In practice, a unique pooled threshold calculated for each pair of legs may be suitable for most situations. However, differences might exist between weighing platforms, and additional work is needed to understand whether these thresholds can be generalized across different systems. The optimal thresholds were not 0 $\mathrm{kg}$ as expected because motion causes weight to drift. They were considerably higher (127 and $98 \mathrm{~kg}$ for the front and rear legs, respectively) than the unvalidated threshold of $20 \mathrm{~kg}$ used by Pastell and Kujala (2007).

Lame cows took more steps per minute with the rear legs than did nonlame cows, whereas no differences were observed in the frequency of steps taken with the front legs. By stepping, a lame cow may be trying to reduce the weight borne by the affected limb. A large portion of lameness is thought to be associated with injuries in the rear hooves (Manske et al., 2002; Cramer et al., 2008); thus, it seems reasonable that the pattern (more stepping associated with lameness) is apparent only in the rear legs. The frequency of steps, calculated using the weight threshold, can be used to discriminate between lame and nonlame cows. The accuracy (ex-
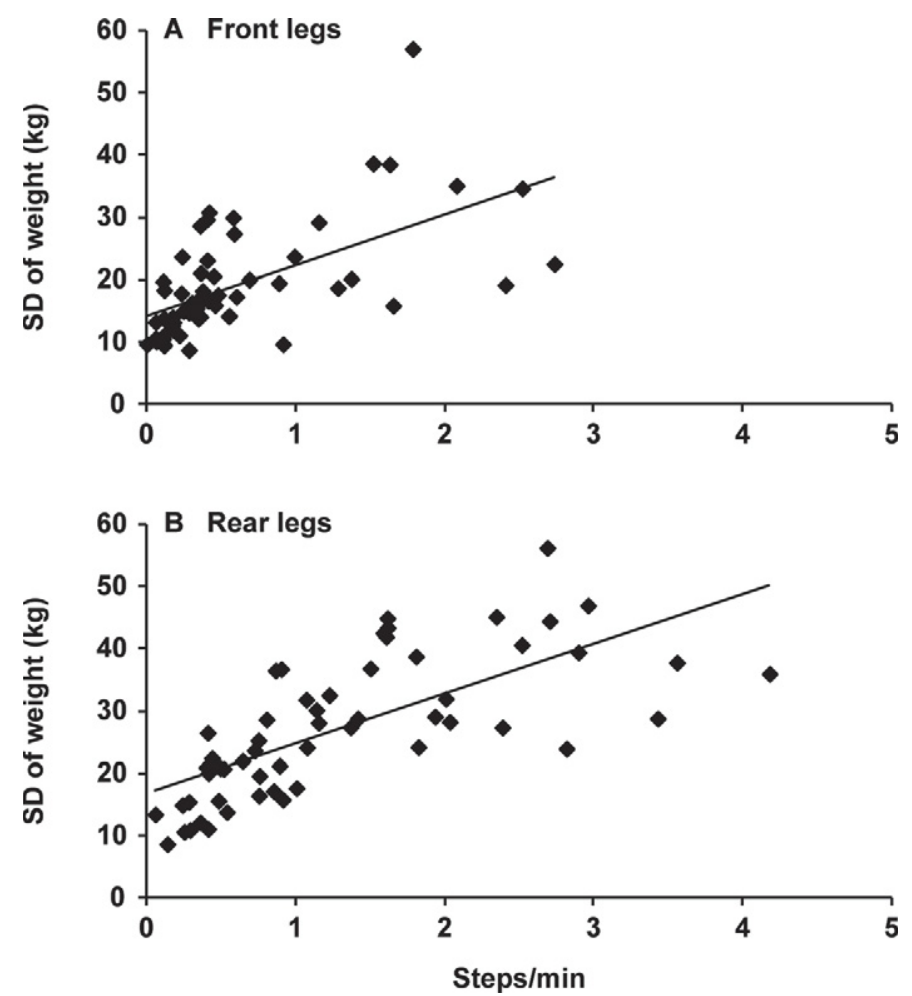

Figure 2. Relationship between the standard deviation of weight applied over time to the legs and the number of steps per minute (as calculated by using the algorithm) for the front $\left(\mathrm{A} ; \mathrm{R}^{2}=0.35 ; P<\right.$ $0.001)$ and rear $\left(\mathrm{B} ; \mathrm{R}^{2}=0.49 ; P<0.001\right)$ pair of legs for 57 multiparous cows. 
pressed as AUC) of the frequency of steps taken with the rear legs in discriminating lame from nonlame cows is in the same range as that for the standard deviation of the weight applied over time to the rear legs (a measure of weight shifting between legs; $\mathrm{AUC}=0.71$ ) and the leg weight ratio between the lighter and the heavier rear leg (a measure of asymmetry within a pair of legs; AUC = 0.69; Chapinal et al., 2010). Similarly, Pastell and Kujala (2007) combined the 3 automated measures (frequency of steps, SD of the weight and leg weight ratio of the rear legs) using a probabilistic neural network model and estimated an AUC of 0.86 . The accuracy of a given measure in discriminating lame cows might depend on the cause of lameness. For instance, Pastell et al. (2010) found an AUC of 0.88 for the leg weight ratio of the rear legs in discriminating cows with altered gait (NRS $\geq 3.5$ ) and an AUC of 0.87 in discriminating cows with an ulcer, but the leg weight ratio could not discriminate cows with dermatitis. This highlights the importance of using multiple measures to assess lameness.

The frequency of steps correlated with other measures of lameness, such as gait score, leg weight ratio, and particularly the standard deviation of the weight applied to the legs. Although the frequency of steps and the standard deviation of the weight applied to the legs are measures of weight distribution; they do not measure exactly the same phenomena (the slope of the relationship was different from 1 and the intercept was different from 0). Although they have a similar accuracy in detecting lameness, it could be helpful to assess both measures for the detection of other diseases. For instance, cows with mastitis may often be restless because of the discomfort caused by the sore udder and shift weight but without stepping to avoid hitting the udder with the legs (Chapinal et al., 2011). The ratio between the standard deviation of the weight and number of steps taken with a pair of legs would be greater in cows with mastitis as compared with healthy cows; therefore, the ratio between the 2 measures may be useful to detect mastitis on farms.

In conclusion, the frequency of steps taken when cows stand without walking has been proved to be a measure of restlessness or discomfort associated with lameness and on periods of forced standing. Weighing platforms are accurate in automatically calculating the frequency of steps, and this measure shows promise as a tool to assess lameness. Further research is needed to assess whether the frequency of steps, in combination with other automated measures of weight distribution, can be used to discriminate among different causes of lameness and to detect other health problems, such as mastitis.

\section{ACKNOWLEDGMENTS}

We thank Jeff Rushen (Agriculture and Agri-Food Canada, Ottawa, ON, Canada), Anne Marie de Passillé (Agriculture and Agri-Food Canada), Sarah Wagner (North Dakota State University, Fargo), Matti Pastell (University of Helsinki, Finland), David Ledgerwood (University of California, Davis), Gosia Zdanowicz (Agriculture and Agri-Food Canada), and all the staff at The University of British Columbia Dairy Education and Research Centre (Vancouver, Canada) for their help in conducting the study, processing the data, and discussing the manuscript. The research was funded by the University of California, Davis; Global Animal Partnership (Washington, DC), Natural Sciences and Engineering Research Council of Canada (Ottawa, ON), Agriculture and Agri-Food Canada, and the National Research Initiative of the USDA National Institute of Food and Agriculture (Washington, DC).

\section{REFERENCES}

Chapinal, N., A. M. de Passillé, J. Rushen, and C. B. Tucker. 2011. Measures of weight distribution and frequency of steps as indicators of restless behavior. J. Dairy Sci. 94:800-803.

Chapinal, N., A. M. de Passillé, J. Rushen, and S. Wagner. 2010. Automated methods for the detection of lameness and analgesia in dairy cattle. J. Dairy Sci. 93:2007-2013.

Chapinal, N., A. M. de Passillé, D. M. Weary, M. A. G. von Keyserlingk, and J. Rushen. 2009. Using gait score, walking speed and lying behavior to detect hoof lesions in dairy cows. J. Dairy Sci. 92:4365-4374.

Cooper, M. D., D. R. Arney, and C. J. C. Phillips. 2007. Two- or fourhour lying deprivation on the behavior of lactating dairy cows. J. Dairy Sci. 90:1149-1158.

Cramer, G., K. D. Lissemore, C. L. Guard, K. E. Leslie, and D. F. Kelton. 2008. Herd- and cow-level prevalence of foot lesions in Ontario dairy cattle. J. Dairy Sci. 91:3888-3895.

Dohoo, I., W. Martin, and H. Stryhn. 2009. Veterinary Epidemiologic Research. 2nd ed. VER Inc., Charlottetown, Prince Edward Island, Canada.

Flower, F. C., and D. M. Weary. 2006. Effect of hoof pathologies on subjective assessments of dairy cow gait. J. Dairy Sci. 89:139-146.

Krebs, N., S. L. Berry, and C. B. Tucker. 2011. Restless behavior increases over time, but not with compressibility of the flooring surface, during forced standing at the feed bunk. J. Dairy Sci. 94:97-105.

Manske, T., J. Hultgren, and C. Bergsten. 2002. Prevalence and interrelationships of hoof lesions and lameness in Swedish dairy cows. Prev. Vet. Med. 54:247-263.

NRC. 2001. Nutrient Requirements of Dairy Cattle. 7th rev. ed. Natl. Acad. Press, Washington, DC.

Pastell, M., L. Hänninen, A. M. de Passillé, and J. Rushen. 2010. Measures of weight distribution of dairy cows to detect lameness and the presence of hoof lesions. J. Dairy Sci. 93:954-960.

Pastell, M. E., and M. Kujala. 2007. A probabilistic neural network model for lameness detection. J. Dairy Sci. 90:2283-2292.

Rushen, J., E. Pombourcq, and A. M. de Passillé. 2007. Validation of two measures of lameness in dairy cows. Appl. Anim. Behav. Sci. 106:173-177. 